\title{
Antimosquito Phenylpropenoids from the Stem and Root Barks of Uvariodendron pycnophyllum (Diels) R.E.Fr
}

\section{*11CHARLES KIHAMPA; ${ }^{2}$ MAYUNGA H. H. NKUNYA; ${ }^{2}$ COSAM C. JOSEPH; ${ }^{3}$ STEPHEN M. MAGESA}

\begin{abstract}
${ }^{1}$ Department of Environmental Science and Management, Ardhi University, P.O. Box 35176, Dar es Salaam, Tanzania; ${ }^{2}$ Department of Chemistry, University of Dar es Salaam, P.O. Box 35061, Dar es Salaam, Tanzania; ${ }^{3}$ National Institute for Medical Research, P.O. Box 81, Amani Research Centre, Muheza, Tanga, Tanzania
\end{abstract}

\begin{abstract}
The phenylpropenoids $O$-methyleugenol, $O$-methylisoeugenol and 2,3dimethoxycinnamaldehyde, have been isolated as the antimosquitocidal principles of the stem and root bark extracts of Uvariodendron pycnophyllum (Diels) R.E. Fr. The extracts and compounds exhibited activity with $\mathrm{LC}_{50}$ values in the range 17-59 ppm against the Anopheles gambiae s.s Giles mosquito larvae, while the constituent phenylpropenoids showed long term mortality effects to adult An. gambiae mosquito on impregnated bednets, and mosquito repellency that was stronger than the activity of the standard repellent DEET. @ JASEM
\end{abstract}

Uvariodendron (Family Annonaceae) is a small genus comprising about 16 species, which are either shrubs or trees, the genus being restricted to tropical Africa and about 6 species are confined to East Africa (Verdcourt, 1971). According to the Flora of Tropical East Africa (Verdcourt, 1971), four Uvariodendron species, namely $U$. kirkii, $U$. gorgonis, $U$. pycnophyllum and $U$. usambarense are reported to occur in Tanzania.

In continuation with investigations of Tanzanian plant species for antimosquito constituents as a contribution to control malaria transmission mosquitoes (Kihampa et al., 2009), we have analyzed the root and stem barks of Uvariodendron pycnophyllum (Diels) R.E. Fr. (Mkene in Kiswahili) that in preliminary assays exhibited potent antimosquito activity. We now report the antimosquito properties of $O$-methyleugenol (1), $O$ methylisoeugenol (2), 2,3-dimethoxycinnamaldehyde (3) and stigmasterol (4) obtained from the stem and root bark extracts. Besides being a source of firewood, building poles, knife and hoe handles, beds, bows and withies, the plant species is not used in any folk medicine.

\section{MATERIALS AND METHODS}

Plant Materials: The leaves, stem and root barks of U. pycnophyllum were collected from Siggi Valley, 3 $\mathrm{km}$ from Kisiwani village along the road to Bombani in the Amani Nature Reserve, East Usambara Mountains in Muheza District, Tanga Region. The plant species was identified on site and its identity was further confirmed at the Herbarium of the Department of Botany, University of Dar es Salaam, where a voucher specimen is deposited.

Extraction and Isolation: The air dried and pulverized root and stem barks were extracted sequentially with $\mathrm{CHCl}_{3}$ and $\mathrm{MeOH}, 2$ x $48 \mathrm{~h}$ for each solvent. The extracts were stored at $-18{ }^{\circ} \mathrm{C}$ until further analysed or assayed. The active compounds were isolated following a bioassay-guided isolation from the relevant extracts using the brine shrimp lethality test (BST) (Meyer et al., 1982). Fractionation of the concentrated extracts was carried out by VLC, followed by repeated column chromatography on silica gel and/or Sephadex ${ }^{\circledR}$ LH20 eluting with pet ether and then pet ether containing increasing amounts of EtOAc, and mixtures of $\mathrm{MeOH}$ and $\mathrm{CHCl}_{3}(1: 1, \mathrm{v} / \mathrm{v})$ respectively. Structural determination was achieved upon analysis of spectral data.

Larvicidal Assay: The assay was carried out according to the WHO protocol (WHO, 1996). Twenty late $3^{\text {rd }}$ or young $4^{\text {th }}$ instar larvae were used per beaker with three beakers per concentration (the water temperature being $25 \pm 1^{\circ} \mathrm{C}$ ) and for each test three beakers containing distilled water and test larvae but without sample were used as controls. Larvae mortality and deformities was recorded after every $24 \mathrm{~h}$ of continuous exposure and expressed as percent mortality (WHO, 1996). The lethal concentration at which $50 \%$ of the test larvae were killed $\left(\mathrm{LC}_{50}\right)$ was determined using POLO PLUS computer package.

Mosquitocidal Assay: This was performed as described in the literature (Joseph et al., 2004).

Mosquito Repellency Assay: The assay was conducted as reported in the literature (Innocent et al., 2008) using serial dilutions, the highest concentration being $1 \%(0.01 \mathrm{~g} / \mathrm{ml})$ and the other concentrations were $0.000015,0.00015,0.0015$, 0.015 and $0.15 \mathrm{mg} / \mathrm{cm}^{2}$ corresponding to $10^{-5}, 10^{-4}$, 
$10^{-3}, 10^{-2}$ and $10^{-1} \mathrm{ppm}$ solutions respectively. The screening was done sequentially starting with the lowest dose $(0.001 \%)$ and ending with the highest one $(1 \%)$. A test solution $(0.5 \mathrm{ml})$ was dispensed on the right forearm of a volunteer from the wrist to the elbow. The rest of the hand was covered with glove to make it unattractive to the mosquitoes. Acetone $(0.5 \mathrm{ml})$ was dispensed on the left forearm, to act as control. The arms were swapped regularly to eliminate any bias. The control arm was introduced into the cage immediately after releasing the 25 insects and kept there for $3 \mathrm{~min}$. The mosquitoes that had landed on the untreated control arm were recorded. The treated arm was then introduced into the cage and kept there for $3 \mathrm{~min}$. The number of mosquitoes that landed on the treated arm was also recorded. Each concentration was screened using a fresh batch of mosquitoes. After the bioassay of each concentration, the arms were washed with bar soap, rinsed well with tap water and then allowed to dry for 15-20 min, before application of the next dose of the test sample and the percentage protective efficacy (PE) was calculated as

$$
\mathrm{PE}=\left(\frac{\mathrm{PCM}-\mathrm{PTM}}{\mathrm{PCM}}\right) \times 100 \%
$$

where PCM is the percent control mean and PTM is the percent test mean of mosquitoes landing on the control and treated arms respectively.

Table 1 Larvicidal Activity of $\mathbf{1 , 2}$ and $\mathbf{4}$ Against An. gambiae Larvae

\begin{tabular}{|c|c|c|c|c|c|c|c|c|}
\hline \multirow[b]{2}{*}{ Cp } & \multirow{2}{*}{$\begin{array}{c}T \\
\text { (h) }\end{array}$} & \multicolumn{6}{|c|}{ Concentration (ppm) } & \multirow{2}{*}{$\begin{array}{c}\mathrm{LC}_{50}(\mathrm{ppm}) \\
95 \% \mathrm{CL}\end{array}$} \\
\hline & & 15.62 & 31.25 & 62.5 & 125 & 250 & 500 & \\
\hline 1 & 48 & $80 \pm 5.7$ & $80 \pm 5.7$ & $100 \pm 0$ & $100 \pm 0$ & nd & nd & nd \\
\hline \multirow[t]{3}{*}{2} & 24 & $23.3 \pm 3.3$ & $30 \pm \overline{5} .7$ & $36.7 \pm 8.8$ & $70 \pm 0$ & $90 \pm 0$ & $100 \pm 0$ & $59(34-95)$ \\
\hline & 48 & $53.3 \pm 6.7$ & $66.7 \pm 3.3$ & $93.3 \pm 3.3$ & $100 \pm 0$ & $100 \pm 0$ & & $17(04-26)$ \\
\hline & 72 & $100 \pm 0$ & $100 \pm 0$ & $100 \pm 0$ & nd & nd & nd & nd \\
\hline 4 & 72 & $100 \pm 0$ & $100 \pm 0$ & $100 \pm 0$ & nd & nd & nd & nd \\
\hline UPSC $*$ & - & - & - & - & - & - & - & $56(34-87)$ \\
\hline UPSM* & - & - & - & - & - & - & - & $109(66-192)$ \\
\hline UPRC** & - & - & - & - & - & - & - & $56(34-86)$ \\
\hline UPRM* & - & - & - & - & - & - & - & $56(35-86)$ \\
\hline
\end{tabular}

\section{RESULTS AND DISCUSSION}

Bio-assayed guided fractionation of the antimosquito chloroform extract of the stem bark, and chloroform and methanol extracts of the root barks yielded $O$ methyleugenol (1) and $O$-methylisoeugenol (2) as the major constituents of the root bark, as well as 2,3dimethoxycinnamaldehyde (3) and stigmasterol (4). The stem bark methanol extract was less active than the other three extracts, hence it was not analysed further for constituent compounds. Structures of the isolated compounds were identified based on analysis of spectroscopic data (Mohammed et al., 1985; Mussa, 2000).
The phenylpropenoids 1 and 2, and compound 4 displayed larvicidal activity at different levels (Table 1). There was no significant difference in the observed activity between the tested compounds after $24 \mathrm{~h}$ of larvae exposure. Furthermore, no significant difference in the activity was observed between the three compounds 1,2 and 4, and that of the crude chloroform extracts of the stem and root barks, and that of the root bark methanol extract (Table 1). Compound 3 was not assayed for larvicidal activity due to paucity of the obtained amount. Long term exposure of the larvae to the samples up to $72 \mathrm{~h}$ showed significant increase in larvicidal activity as deduced from the $\mathrm{LC}_{50}$ value after 48 and $72 \mathrm{~h}$ larvae exposure for 1, 2 and 4 (Table 1). 
<smiles>C=CCc1ccc(OC)c(OC)c1</smiles><smiles>C/C=C/c1ccc(OC)c(OC)c1</smiles>

Compounds 1 and 2 were also assayed for activity against adult mosquitoes in the tarsal contact and repellency bioassays. Table 2 shows that after $3 \mathrm{~min}$ exposure compounds 1 and 2, and the standard insecticide Fendona ${ }^{\circledR}$ were inactive against $A n$. gambiae mosquitoes in all the tested concentrations. After $1 \mathrm{~h}$ holding time compounds 1 and 2 exhibited a knock down effect of 30 and $10 \%$ respectively at the highest concentration tested $\left(200 \mathrm{mg} / \mathrm{m}^{2}\right)$. At the same time interval $(1 \mathrm{~h})$ the standard insecticide showed strong activity even at the lowest concentration tested $\left(100 \mathrm{mg} / \mathrm{m}^{2}\right)$, the knock down effect being $80 \%$. The mortality caused by the standard insecticide tended to decrease with extension of holding time but the activity for compounds 1 and 2 showed an increasing trend. These results suggest that compounds 1 and 2 could be interesting candidates for the development of bednet impregnated mosquitocides.

Table 2 Insecticidal Activity of $\mathbf{1}, \mathbf{2}$ and Fendona ${ }^{\circledR}$ Against An. gambiae Mosquito

\begin{tabular}{ccccccc}
\hline & Time & \multicolumn{5}{c}{ \% Mortality/Concentration $\left(\mathbf{m g} / \mathbf{m}^{2}\right)$} \\
\cline { 2 - 6 } Compound & $\mathbf{1 0 0}$ & $\mathbf{1 2 5}$ & $\mathbf{1 5 0}$ & $\mathbf{1 7 5}$ & $\mathbf{2 0 0}$ \\
\hline $\mathbf{1}$ & $3 \mathrm{~min}$ & $0 \pm 0$ & $0 \pm 0$ & $0 \pm 0$ & $0 \pm 0$ & $20 \pm 0$ \\
& $1 \mathrm{~h}$ & $0 \pm 0$ & $0 \pm 0$ & $0 \pm 0$ & $0 \pm 0$ & $30 \pm 3.3$ \\
& $24 \mathrm{~h}$ & $0 \pm 0$ & $10 \pm 3.3$ & $20 \pm 0$ & $30 \pm 0$ & $40 \pm 5.8$ \\
& $48 \mathrm{~h}$ & $0 \pm 0$ & $10 \pm 0$ & $20 \pm 5.8$ & $20 \pm 5.8$ & $30 \pm 0$ \\
$\mathbf{2}$ & $3 \mathrm{~min}$ & $0 \pm 0$ & $0 \pm 0$ & $0 \pm 0$ & $0 \pm 0$ & $0 \pm 0$ \\
& $1 \mathrm{~h}$ & $0 \pm 0$ & $0 \pm 0$ & $0 \pm 0$ & $0 \pm 0$ & $10 \pm 0$ \\
& $24 \mathrm{~h}$ & $0 \pm 0$ & $10 \pm 0$ & $20 \pm 0$ & $20 \pm 0$ & $30 \pm 5.8$ \\
& $48 \mathrm{~h}$ & $10 \pm 0$ & $40 \pm 0$ & $40 \pm 0$ & $40 \pm 0$ & $50 \pm 0$ \\
Fendonayyyy$^{\circledR}$ & $3 \mathrm{~min}$ & $0 \pm 0$ & $0 \pm 0$ & $0 \pm 0$ & $0 \pm 0$ & $0 \pm 0$ \\
& $1 \mathrm{~h}$ & $80 \pm 0$ & $80 \pm 11.5$ & $80 \pm 11.5$ & $100 \pm 0$ & $100 \pm 0$ \\
& $24 \mathrm{~h}$ & $46.7 \pm 6.7$ & $80 \pm 11.5$ & $80 \pm 0$ & $80 \pm 0$ & $100 \pm 0$ \\
& $48 \mathrm{~h}$ & $30 \pm 0$ & $66.7 \pm 6.7$ & $80 \pm 0$ & $80 \pm 0$ & $80 \pm 0$ \\
\hline
\end{tabular}

In the mosquito repellency assays, the activity of compounds 1 and 2 were compared to those of the standard repellent DEET (Table 3 and Figure 1). The graph in Figure 1 shows that the activity trend of the two compounds was almost linear. The repellency and 4 were not tested in the tarsal contact and repellency activity due to paucity of the amount isolated.

Table 3 Repellency Activity of the Isolated Compounds and DEET

\begin{tabular}{ccccccc}
\hline \multirow{2}{*}{ Compound } & \multicolumn{4}{c}{ Percentage Repellency/Concentration $(\mathbf{m g} / \mathbf{m l})$} & \multirow{2}{*}{$\mathbf{R C}_{\mathbf{5 0}}\left(\mathbf{m g} / \mathbf{c m}^{\mathbf{2}}\right)$} \\
\cline { 2 - 5 } & $\mathbf{1 0}^{-\mathbf{5}}$ & $\mathbf{1 0}^{-4}$ & $\mathbf{1 0}^{-\mathbf{3}}$ & $\mathbf{1 0}^{-\mathbf{2}}$ & $\mathbf{1 0}^{-\mathbf{1}}$ & \\
\hline $\mathbf{1}$ & $45 \pm 1.7$ & $71 \pm 1.2$ & $91 \pm 0$ & $100 \pm 0$ & $100 \pm 0$ & $5.84 \times 10^{-6}$ \\
$\mathbf{2}$ & $25 \pm 1.2$ & $46 \pm 0$ & $74 \pm 0.6$ & $85 \pm 0.6$ & $92 \pm 0$ & $1.58 \times 10^{-4}$ \\
DEET & $0 \pm 0$ & $41 \pm 5.8$ & $4 \underline{6} \pm 0$ & $98 \pm 5.8$ & $100 \pm 0$ & $6.12 \times 10^{-4}$ \\
\hline
\end{tabular}




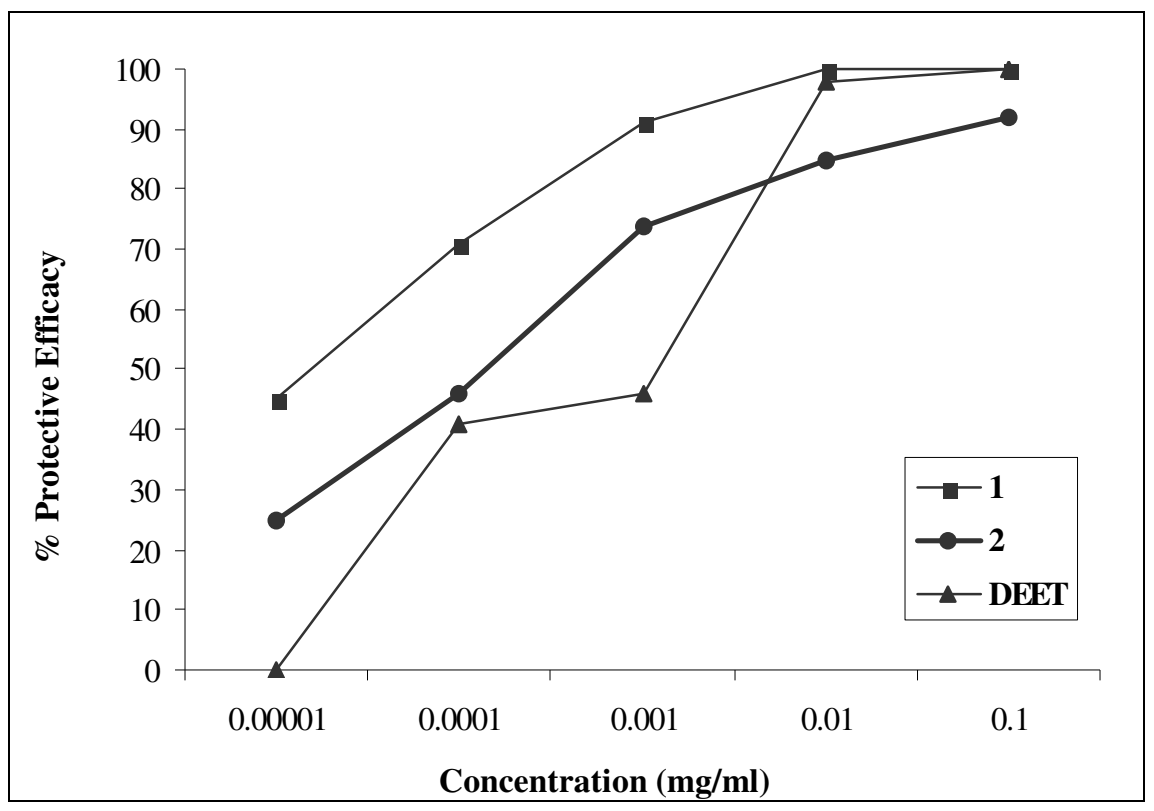

Fig.1 .. Percentage Variation of Mosquito Repellency Efficacy of Compounds 1, 2 and DEET Against An. gambiae Mosquitoes

Acknowledgement: We thank the Germany Academic Exchange Services (DAAD) for a study grant for the research work that was also undertaken at Amani Medical Research Center in Muheza, Tanga, Tanzania. Financial support through Sida/SAREC support to the Faculty of Science at the University of Dar es Salaam is gratefully acknowledged. We thank Mr. Frank Mbago of the Herbarium, Department of Botany at the University of Dar es Salaam for location and identification of the investigated plant species.

\section{REFERENCES}

Innocent, E; Gikonyo, NK; Nkunya, MHH (2008). Repellency property of long chain aliphanic methyl ketones against Anopheles gambiae s.s. Tanzania. J Health Res 10: 50-54.

Joseph, CC; Ndoile, MM; Malima, RC; Nkunya, MHH (2004). Larvicidal and mosquitocidal extracts, a coumarin, isoflavonoids and pterocarpans from Neorautanenia mitis. Trans. Royal Soc Trop Med Hyg 98: 451455.

Kihampa, C; Joseph, CC; Nkunya, MHH; Magesa, SM; Hassanali, A; Heydenreich, M; Kleinpeter, E (2009). Larvicidal and IGR activity of extract of Tanzanian plants against malaria vector mosquitoes. J Vector Borne Dis 46: 145-152.
Mohammed, I; Waterman, PG (1985). Chemistry in the Annonaceae, XVII. Phenylpropenes from Uvariodendron connives seeds. J Nat Prod 48: 328-329.

Mussa, LM (2000). Flavonoids, eugenol derivatives and terpenoids from three coastal plants of Annonaceae. MSc Thesis, University of Dar es Salaam.

Meyer, BN; Ferrigni, NR; Putnam, JE; Jacobsen, LB; Nichols, DE; McLaughlin, JL (1982). Brine Shrimp: A convenient general bioassay for active plant constituents. Planta Med 45: $31-$ 34

Verdcourt, B (1971). Flora of Tropical East Africa: Annonaceae. Crown Agents, London.

WHO (1996). Report of the WHO informal consultation on the evaluation and testing of insecticides. WHO, Geneva, pp 32-36 and 5052. 